\title{
Radiotracer Estimation of Microbial Biomass in Lake Sediment
}

\author{
Gerald G. Marten \\ Environment and Policy Institute, East-West Center, Honolulu, HI 96848, USA
}

\begin{abstract}
Marten, G. G. 1985. Radiotracer estimation of microbial biomass in lake sediment. Can. J. Fish. Aquat. Sci. 42: 373-379.

The biomass of sediment organisms can be measured by allowing carbon tracer to distribute itself through sediment cores. Application of this method to sediment from Marion Lake, British Columbia, indicated that most of the sediment microorganisms were concentrated in the top $2 \mathrm{~cm}$ of sediment, where the total biomass of microorganisms was estimated to be $183 \mu \mathrm{g} \mathrm{C} / \mathrm{cm}^{2}$. The radiotracer estimate compared favorably with independent measurements based on ATP and direct microscopic counts of sediment microorganisms.
\end{abstract}

On peut quantifier la biomasse des organismes sabulicoles en permettant la distribution d'un traceur au carbone dans des carottes sédimentaires. L'application de cette méthode à des sédiments recueillis dans le lac Marion (C.-B.) a révélé que la plupart des microorganismes étaient concentrés ans les premiers $2 \mathrm{~cm}$ où 
la biomasse total s'élevait à $183 \mu \mathrm{g} \mathrm{C} / \mathrm{cm}^{2}$. Cette valeur se rapproche de quantifications indépendantes basées sur la détermination du volume d'ATP et le dénombrement des microorganismes à l'aide d'un microscope.

Received September 28, 1982

Accepted October 22, 1984 (J7075)
Reçu le 28 septembre 1982

Accepté le 22 octobre 1984
$\mathbf{E}$ stimating the biomass of sediment microorganisms is basic to studying their ecology, but it is not a simple matter. The most straightforward approach would be to separate microorganisms from the sediment and weigh them or measure their carbon content. Although there are possibilities for separation using sonification (Puleo et al. 1967), complete separation has not yet proven feasible, particularly when the microorganisms are thoroughly enmeshed with detritus. Rodina (1972), Sorokin and Kadota (1972), Collins (1977), and Jones (1977) have reviewed current methodologies for measuring microbial biomass, and two methods appear to provide the best estimates: (1) direct counts by fluorescent microscopy; (2) ATP assay.

Unfortunately, even these two methods have some serious limitations. Direct counts may fail to distinguish active microorganisms from spores; and minor alterations in fluorescent staining technique can sometimes lead to significant changes in the count (Jones 1974). Furthermore, translating counts to biomass requires an estimation of the size distribution of the microbial population and conversion factors from cell volume to biomass, which may not be known precisely for the samples in hand. ATP assay has been used to estimate the total living biomass in a sample, based on the apparent similarity of the carbon/ATP ratio for a wide variety of organisms (HolmHansen and Booth 1966). However, the precision of this method is still uncertain because the carbon/ATP ratio has in fact been observed to vary from 25 to 2000 , depending upon the organism and environmental conditions, though the carbon/ ATP ratio appears to be 200-300 for many bacteria (Karl 1980).

This report describes a radiotracer approach to measuring the biomass of sediment microorganisms which may overcome some of the limitations of existing methods.

\section{Methods}

The measurement of biomass with radiotracers is based upon the principle that, given sufficient time, a radiotracer will distribute itself throughout an ecosystem in proportion to the element it is tracing. If a carbon tracer is introduced to a sediment core sample, the tracer should eventually distribute itself in proportion to the actively circulating carbon in the core. The vertical distribution of the tracer should reflect the vertical distribution of actively circulating carbon in the sediment core, and the distribution of tracer between particulate and dissolved fractions should reflect the amount of carbon in living biomass compared with other forms of actively circulating carbon such as $\mathrm{CO}_{2}$. If the quantity of dissolved inorganic carbon (DIC) can be measured directly, then it should be possible to infer the absolute amount of carbon in the living biomass by using the following simple proportion:

$$
\frac{\text { Total living particulate carbon }}{\text { Total DIC }}=\frac{\text { Tracer in particles }}{\text { Tracer in DIC }} .
$$

Description of the sediment - The sediment in this study was collected at a water depth of $1 \mathrm{~m}$ in Marion Lake, a small, shallow, oligotrophic lake in British Columbia (Efford 1972; Hall and Hyatt 1974). The sediment was $40 \%$ organic matter by dry weight and originated as mineral particles, aquatic macrophytes, epibenthic algae, leaves, and other forms of detritus that washed into the lake and were consumed and reconsumed by detritivores such as the amphipod Hyalella azteca. The top of the sediment was bare except for occasional strands of filamentous green algae (Gruendling 1971). Although fungi were numerous among newly decomposing leaves at the lake shore, they were not a significant part of the microflora in the more thoroughly processed detritus which occurred at a depth of $1 \mathrm{~m}$ (Dick 1971).

The sediment consisted largely of detritivore feces, small porous particles averaging $50-200 \mu \mathrm{m}$ in diameter and containing macrophyte and diatom fragments held together by amorphous brown organic matter. Fluorescent microscopy of sectioned sediment revealed an abundance of bacteria (typically $1 \mu \mathrm{m}$ in diameter) and microscopic blue-green algae (typically $2-5 \mu \mathrm{m}$ in diameter) adhering to the outer and inner surfaces of the sponge-like sediment particles. The bacteria were much more numerous than the blue-green algae and tended to occur in clusters of about 100 individuals. The surface covered by bacteria appeared to be only a fraction of the total surface area inside and outside the particles. In addition to algae and bacteria, the living biomass in the sediment included protozoa and tiny animals such as rotifers, nematodes, and copepods, restricted for the most part to the aerobic zone in the top $2 \mathrm{~cm}$ of sediment.

Experimental procedure - A series of sediment core samples was taken with as little disturbance as possible in clear plastic cylinders $1.8 \mathrm{~cm}$ in diameter and $6 \mathrm{~cm}$ long with $1 \mathrm{~cm}$ of air and $1 \mathrm{~cm}$ of water above the sediment. The water above the surface of the sediment in two of the cylinders was sampled for dissolved oxygen. The sediment interstitial water was extracted by suction filtration, and along with surface water, was sampled to measure DIC and dissolved organic carbon (DOC) with an infrared gas analyzer. The same measurements were made on additional cores after they were stoppered at the top and bottom for 2 or $3 \mathrm{wk}$ as described below.

Sediment samples were taken from two of the cores at $1-\mathrm{cm}$ intervals to a depth of $5 \mathrm{~cm}$ below the mud-water interface. The samples were placed in flasks containing $\left[{ }^{14} \mathrm{C}\right]$ glucose to measure microbial activity, $K_{\max }$ of Michaelis-Menton kinetics, following the procedure described by Hall et al. (1972) for measuring heterotrophic uptake of organic solutes by mixed sediment. Samples from two additional cores were placed in flasks containing ${ }^{14} \mathrm{CO}_{2}$ to measure microbial activity based on $\mathrm{CO}_{2}$ uptake.

The rest of the cores were used to estimate biomass by 


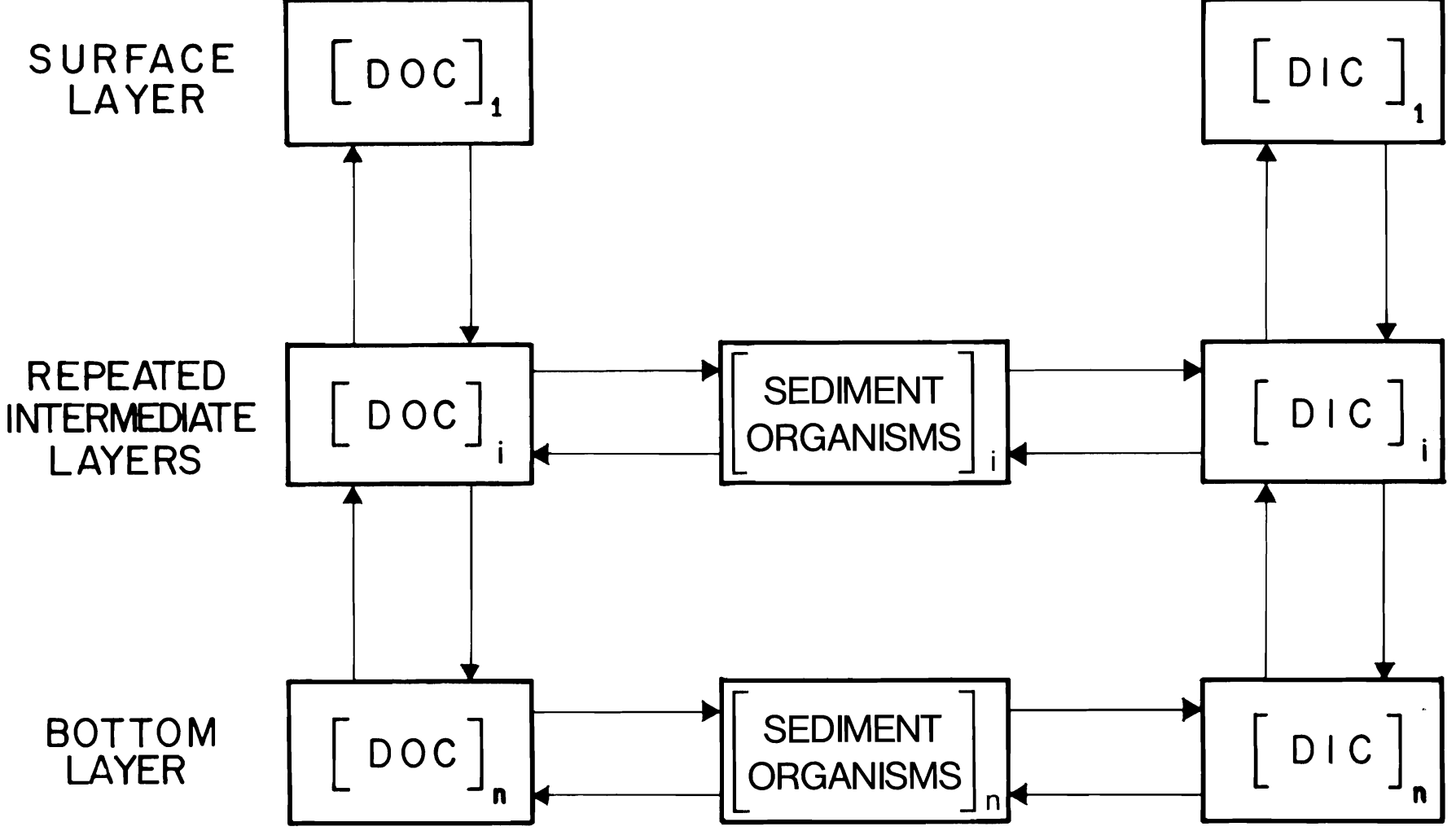

Fig. 1. Conceptual model for the vertical movement of carbon tracer through the sediment and between dissolved inorganic carbon (DIC), dissolved organic carbon (DOC), and particulate (i.e. living organism) fractions at any one depth.

allowing a carbon tracer to distribute itself through the core. $\left[{ }^{14} \mathrm{C}\right]$ Glucose and ${ }^{14} \mathrm{CO}_{2}$ were considered particularly appropriate substrates for introducing carbon tracer to the cores because they are utilized by a great variety of microorganisms (Strzelczyk et al. 1974; Atlas and Bartha 1981). Carbon tracer was also introduced as $\left[{ }^{14} \mathrm{C}\right]$ acetate.

$\left[{ }^{14} \mathrm{C}\right]$ Glucose $(37 \mathrm{kBq})$ was placed in the surface water of three of the cores, and $37 \mathrm{kBq}$ of $\left[{ }^{14} \mathrm{C}\right]$ glucose was injected at the same time into the bottom (i.e. $4 \mathrm{~cm}$ below the sediment surface) of three additional cores. One of the three cores of each treatment was injected throughout with formalin and served as a killed blank. The cores were held for $3 \mathrm{wk}$ at $15^{\circ} \mathrm{C}$ under a $12 \mathrm{~h}$ light : $12 \mathrm{~h}$ dark cycle at $15^{\circ} \mathrm{C}$. The cylinders were stoppered at both ends, but the top stopper was removed for a few seconds each day to renew the air bubble above the water and maintain aerobic conditions at the sediment surface. ${ }^{14} \mathrm{CO}_{2}(148 \mathrm{kBq}$ in the form of $\left[{ }^{14} \mathrm{C}\right]$ bicarbonate) was placed in the surface water of three additional cores, and $37 \mathrm{kBq}$ of $\left[{ }^{14} \mathrm{C}\right]$ acetate was placed in the surface water of another three cores. The cores receiving ${ }^{14} \mathrm{CO}_{2}$ and $\left[{ }^{14} \mathrm{C}\right]$ acetate were treated the same as those receiving glucose except they were terminated after $2 \mathrm{wk}$ instead of $3 \mathrm{wk}$.

The experiment was terminated by freezing the cores in liquid nitrogen and slicing into $0.5-\mathrm{cm}$ segments. Each segment was separated into particulate, DOC, and DIC fractions by the following procedure. First, a segment was placed in $10 \mathrm{~mL}$ of distilled water and acidified to drive off $\mathrm{CO}_{2}$, and the $\mathrm{CO}_{2}$ was collected in glass fiber filters saturated with hyamine hydroxide. The remaining solution was filtered through a $0.22-\mu \mathrm{m}$ Millipore filter. The glass fiber filters (containing DIC) and a subsample of the filtrate (containing DOC) were each placed in vials of Bray's solution for scintillation counting. The Millipore filter (which contained the particulate fraction) was combusted to $\mathrm{CO}_{2}$ and prepared for scintillation counting by the method of Burnison and Perez (1974).

Carbon tracer in the sediment fraction was assumed to represent the amount of tracer in sediment organisms. This assumption requires that significant quantities of tracer did not leak from the particulate to DOC fraction due to cell lysis during the freezing and thawing process. It also assumes that significant quantities of tracer were not present in particulate materials other than living organisms (e.g. detritus particles). Tracer activity in the sediment fraction of the formalin blanks was negligible, indicating that tracer activity in the sediment fraction was due almost entirely to uptake by living organisms rather than physical processes such as adsorption of tracer on sediment particles. It was also verified by autoradiography that carbon tracer was instantly taken up by sediment microorganisms. Carbon tracer in the particulate fraction could be in the microorganisms themselves or in extracellular organic matter such as mucopolysaccharides, whose deposition on sediment particles is mediated by microorganisms (Hobbie and Lee 1980).

Tracer diffusion equation - It is easy to determine whether tracer equilibrium has been reached; if it has, the vertical distribution of tracer in the cores is the same regardless of whether it was introduced at the top or bottom of the cores. If equilibrium has not occurred, then two distinct processes must be taken into account to interpret the results (Fig. 1). First, tracer in solution (i.e. DIC and DOC) diffuses vertically through a sediment core. Second, at each depth there is an exchange of tracer between living organisms in the sediment and tracer in solution.

Although the vertical diffusion process is spatially contin- 


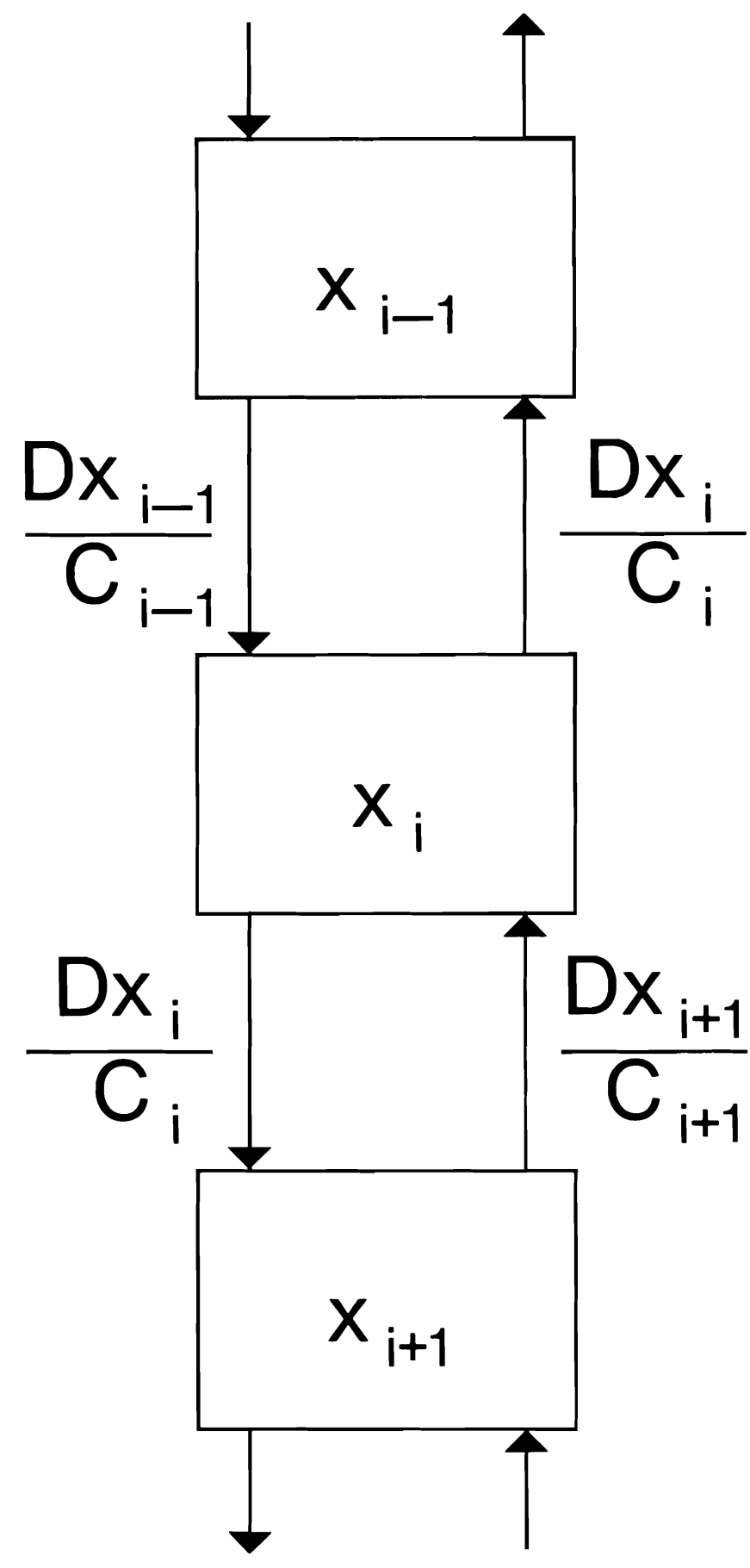

FIG. 2. Model of the vertical movement of carbon tracer with DIC, DOC, and particulate carbon pooled into a single category $\left(\mathrm{C}_{i}\right)\left(x_{i}\right.$ is the amount of carbon tracer and $D$ is a diffusion coefficient).

uous, it is convenient as an approximation to divide the process into vertical segments which correspond to the slices used to sample a core at the end of the experiment. The process can then be described in terms of the movement of tracer between each segment and its neighbor segments (Fig. 1). At this point it is useful to make a simplification, which assumes that equilibration between microorganisms and dissolved carbon at any one depth in the core is fast enough to allow separate consideration of (a) the relatively rapid exchange between living organisms and dissolved carbon (horizontal arrows in Fig. 1) and (b) the relatively slow vertical diffusion process. This important assumption - a rapid equilibrium between microorganisms and dissolved carbon at each depth in the sediment - was verified by injecting broadly labelled DOC into a series of cores and sampling the interstitial water at hourly intervals. Most of the labelled DOC disappeared within an hour, and the tracer approached equilibrium well within a few hours. When ${ }^{14} \mathrm{CO}_{2}$ was injected into cores or placed into the water above the sediment, the ${ }^{14} \mathrm{CO}_{2}$ approached equilibrium within $24 \mathrm{~h}$.

The assumption of horizontal equilibrium allows us to suppose that at the end of a 2-or 3-wk experiment the distribution of carbon between microflora, DOC, and DIC within a vertical layer is simply in proportion to the distribution of carbon tracer in that sediment, even if the tracer has not yet reached vertical equilibrium. We are then free to concentrate on the vertical diffusion process, which may not reach equilibrium so quickly. Each box in Fig. 2 combines microorganisms, DOC, and DIC into a single category: the total mass of actively circulating carbon $\left(\mathrm{C}_{i}\right)$ in the $i$ th vertical sediment. $\mathrm{C}_{i}$ does not include carbon in nonliving detritus and humic compounds, which are not actively circulating.

The vertical diffusion process may then be described by the following "diffusion equation":

$$
\frac{d x_{i}}{d t}=D\left[\frac{x_{i+1}}{C_{i+1}}+\frac{x_{i-1}}{C_{i-1}}-\frac{2 x_{i}}{C_{i}}\right]
$$

where $x_{i}=$ the total amount of carbon tracer in the $i$ th vertical layer and $D=$ a diffusion coefficient which results from both physical and biological processes (including the stirring effect of small animal activity).

The first two terms of the equation represent the diffusion of tracer into the $i$ th layer from the two adjacent layers (Fig. 2), and the last term represents a corresponding diffusion of tracer out of the $i$ th layer. The diffusion equation describes the vertical movement of tracer through a sediment core, a key feature of the process being that the movement of tracer through the core is retarded when the tracer is taken up by microorganisms that must again release it into solution before it can diffuse to an adjacent vertical segment.

We want to ask, "What values of $D$ and $C_{i}$ generate a solution whose $x_{i}$ are closest to the observed vertical distribution of carbon tracer?" The mathematical problem is to fit the system of differential equations to the experimental data, in our case the vertical distribution of tracer 2 or $3 \mathrm{wk}$ after introducing the tracer into the top and bottom of different sediment cores. The diffusion equation was fitted by means of a computer program for tracer kinetics described by Marten et al. (1975).

Once calculated, the $C_{i}$ provide relative estimates of the total actively circulating carbon (DOC + DIC + living organisms) in each vertical layer. Assuming horizontal equilibrium within each layer, the carbon in each layer can be assigned in direct proportion to the amount of tracer in the DOC, DIC, and particulate fractions. Absolute values can be assigned on the basis of direct measurements of DIC.

\section{Results}

The oxygen concentration of the water above the sediment remained near saturation during the cores' 2- or 3-wk incubation periods. The average DOC content of the top $5 \mathrm{~cm}$ of sediment interstitial water was $14 \mu \mathrm{g} \mathrm{C} / \mathrm{mL}$ immediately after removal from the lake bottom and $15 \mu \mathrm{g} \mathrm{C} / \mathrm{mL}$ after $3 \mathrm{wk}$. Average DIC remained at $7 \mu \mathrm{g} \mathrm{C} / \mathrm{mL}$. 


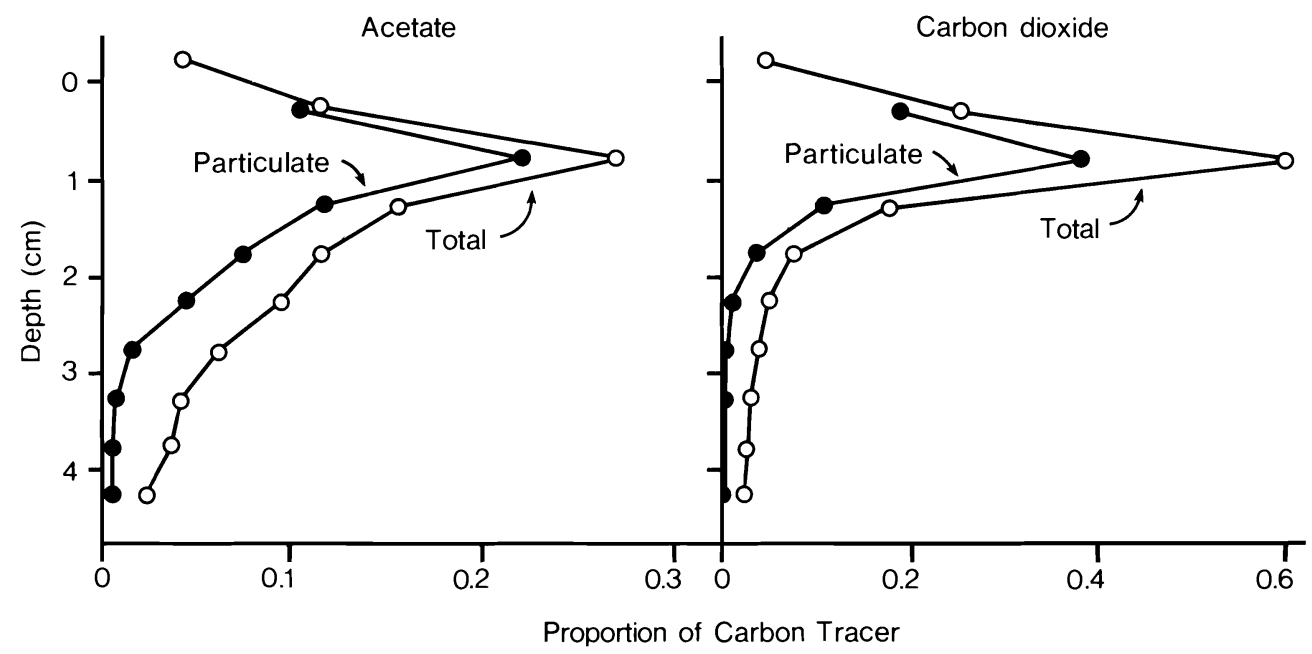

FIG. 3 Vertical distribution of carbon tracer $\left(x_{i}\right) 2 \mathrm{wk}$ after introduction as $\left[{ }^{14} \mathrm{C}\right]$ acetate or ${ }^{14} \mathrm{CO}_{2}$ to the water above the sediment. "Particulate" reflects the amount of tracer in sediment organisms. "Total" includes DIC and DOC fractions as well. The top point corresponds to water immediately above the sediment.

\section{Glucose}

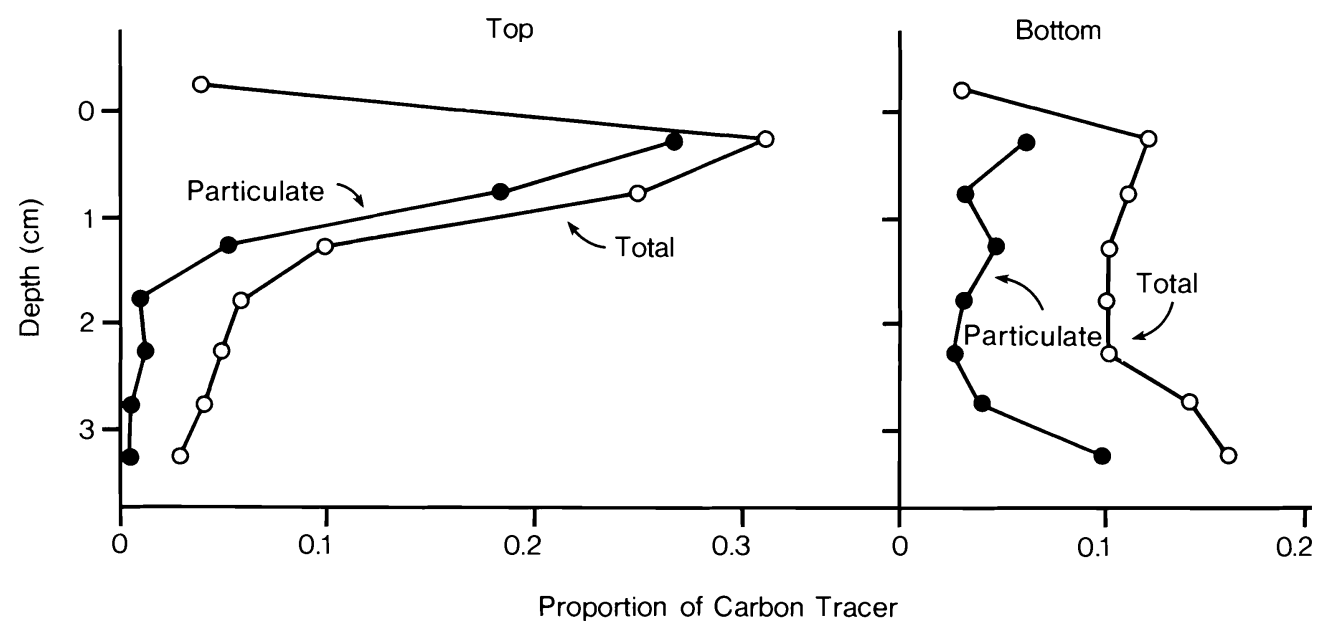

FIG. 4. Vertical distribution of carbon tracer $\left(x_{i}\right) 3 \mathrm{wk}$ after introduction as $\left[{ }^{14} \mathrm{C}\right]$ glucose to the water above the sediment (top) or injection at the bottom of a sediment core (4-cm depth). Other conventions as in Fig. 3.

Vertical distribution of the living biomass - The vertical distribution of tracer 2 or $3 \mathrm{wk}$ after being introduced into the top of the cores was the same whether the initial substrate was acetate, $\mathrm{CO}_{2}$, or glucose (Fig. 3, 4), but the vertical distribution of tracer introduced at the top was radically different from tracer introduced at the bottom (Fig. 4). This meant that vertical equilibrium could not be assumed, so the diffusion equation was used to interpret the results in Fig. 4. The differences between the vertical distribution of tracer introduced at the top and bottom of cores appears to be in part a consequence of a very slow rate of vertical tracer diffusion in solution, since the tracer in formalin blanks did not distribute evenly through the cores in a 3-wk period. However, if only slow diffusion were responsible for the difference, the vertical distribution of tracer introduced from the bottom would be the mirror image of tracer introduced from the top. This was not so (Fig. 4), apparently because the carbon tracer was also intercepted by the sediment's living biomass.
Figure 5 shows the fit of the diffusion equation to the data in Fig. 4. The fit was made simultaneously to the vertical distribution of total carbon tracer (particulate plus DIC and DOC) in cores to which $\left[{ }^{14} \mathrm{C}\right]$ glucose was introduced at the top and cores to which $\left[{ }^{14} \mathrm{C}\right]$ glucose was introduced at the bottom. The fit is so close that the estimated values for relative $\mathrm{C}_{i}$, shown as total carbon in Fig. 5, generated expected values of vertical tracer distribution $\left(x_{i}\right)$ that could not be plotted separately from the observed values of $x_{i}$ in Fig. 4. The close fit suggests that even though tracer movement is a consequence of complex and spatially heterogeneous processes, the diffusion equation can provide a satisfactory empirical description of tracer movement through a sediment core, thereby providing a basis for measuring the vertical distribution of total actively circulating carbon in the core.

Once the total actively circulating carbon (i.e. living organisms, DIC, and DOC) at each depth in the sediment had been estimated, it was then necessary to estimate the amount of that 


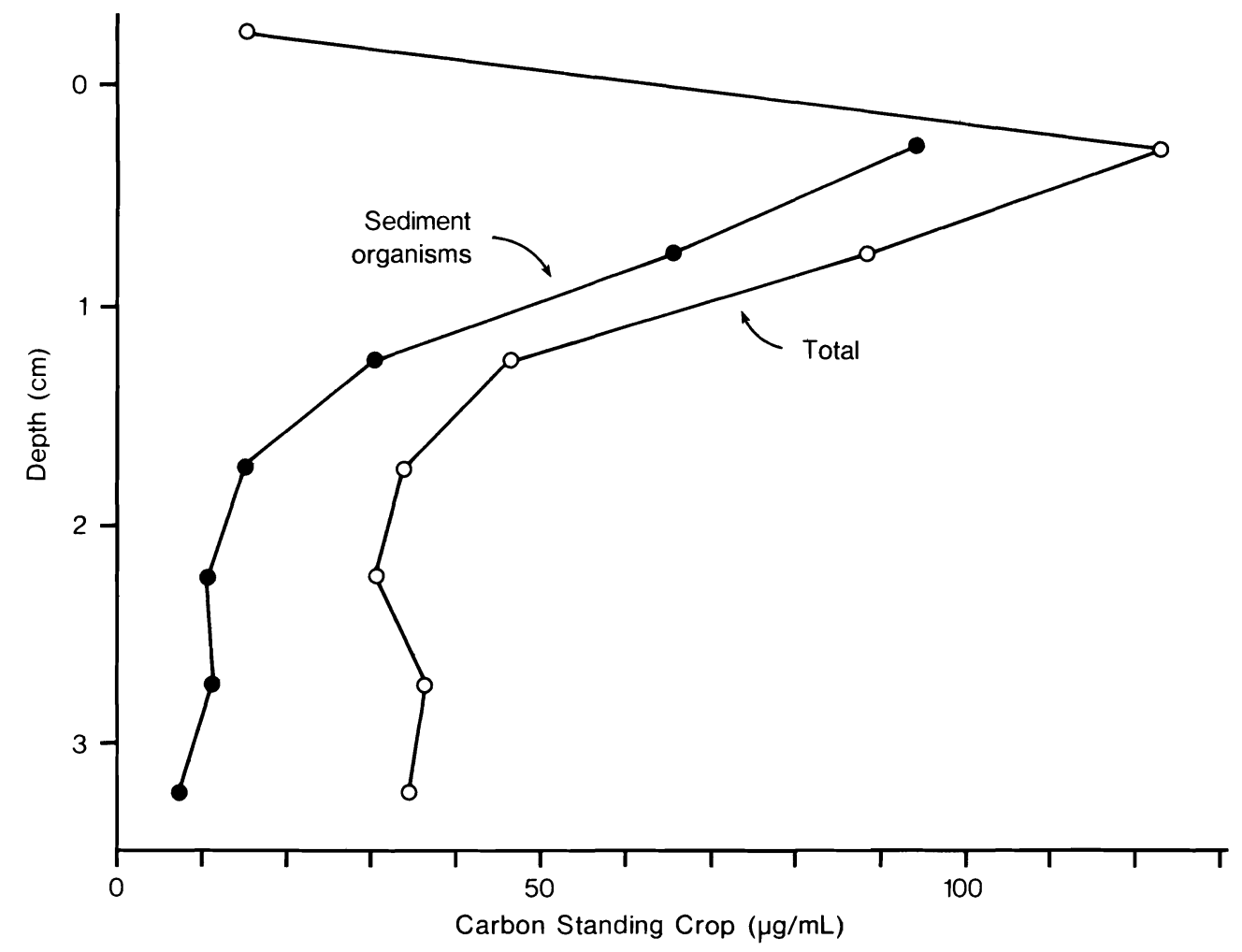

FIG. 5. Estimated biomass of sediment organisms. Also shown is $\mathrm{C}_{i}$, the estimated vertical distribution of total actively circulating carbon (i.e. sediment organisms plus DIC and DOC). The top point corresponds to water immediately above the sediment.

carbon which could be attributed to living organisms. Drawing on the assumption of tracer equilibrium between particulate and solution fractions at any particular depth within the sediment, the total carbon at each depth was assigned to living biomass in simple proportion to the average percentage of tracer observed in the particulate fraction at that depth in the core. Figure 5 shows that most of the living biomass was concentrated in the top $2 \mathrm{~cm}$ of sediment, though smaller quantities persisted to greater depths. The biomass in the water above the sediment was considerably less than in the sediment below. Like the living biomass, actively circulating DOC was concentrated near the sediment surface, but DIC was more uniformly distributed throughout the sediment with a slight peak near the surface. There was less carbon tracer in DOC than in DIC, particularly at greater depths. However, infrared carbon analysis measured overall DOC concentrations to be greater than DIC, suggesting that some of the DOC, particularly at greater depths, was not circulating and therefore not labelled with tracer.

The absolute values in Fig. 5 were assigned so the estimated overall amount of DIC was the same as the overall amount measured directly by carbon analysis of interstitial water from the cores (i.e. $7 \mu \mathrm{g} \mathrm{C} / \mathrm{mL}$ ). The biomass in the top $5 \mathrm{~cm}$ of sediment was estimated to be $250 \mu \mathrm{g} \mathrm{C} / \mathrm{cm}^{2}$, nearly all of it $\left(200 \mu \mathrm{g} \mathrm{C} / \mathrm{cm}^{2}\right)$ in the top $2 \mathrm{~cm}$. Subtracting $17 \mu \mathrm{g} \mathrm{C} / \mathrm{cm}^{2}$ for meiofauna (based on direct counts by Hoebel 1978), the estimated biomass of microorganisms in the top $2 \mathrm{~cm}$ is $183 \mu \mathrm{g}$ $\mathrm{C} / \mathrm{cm}^{2}$. Virtually all the microorganism biomass should be bacteria and algae, since the estimated protozoan biomass (based on direct counts by Kool 1975) was only $0.1 \mu \mathrm{g} \mathrm{C} / \mathrm{cm}^{2}$.

\section{Discussion}

The radiotracer estimates of living biomass in Fig. 5 can be compared with estimates obtained by other methods on sediment samples from the same location. The vertical distribution of biomass in Fig. 5 is similar to that of microbial activity in Fig. 6 , and it is also similar to the vertical pattern of bacterial counts reported by Hall and Hyatt (1974). The biomass estimate of 183 $\mu \mathrm{g} \mathrm{C} / \mathrm{cm}^{2}$ for microorganisms in the top $2 \mathrm{~cm}$ of sediment is close to an estimate of $150 \mu \mathrm{g} \mathrm{C} / \mathrm{cm}^{2}$ based on ATP (Perry 1974). It is somewhat higher than an estimate of $119 \mu \mathrm{g} \mathrm{C} / \mathrm{cm}^{2}$ based on direct count estimates of $79 \mu \mathrm{g} \mathrm{C} / \mathrm{cm}^{2}$ for bacteria (Perry 1974) and $40 \mu \mathrm{g} \mathrm{C} / \mathrm{cm}^{2}$ for algae (Greundling 1971).

Although the general agreement among these methods is reassuring, it does not prove that any one of them is measuring the biomass of sediment microorganisms with a high degree of precision. The radiotracer method will require considerably more validation, and possibly substantial modification, before it can be used with confidence.

There are a number of ways that radiotracer estimation of microbial biomass might be improved. First, even though the vertical diffusion equation seems to work, it would be best to get along without it. In other words, it would be best to use only tracer measurements that reflect full tracer equilibrium, making the diffusion equation unnecessary. One way to hasten vertical equilibrium could be to distribute the tracer vertically throughout the sediment by introducing the tracer through a vertical series of injection portals in the plastic cylinder that holds a sediment core.

Second, it might be possible to bypass the issue of vertical equilibrium by directly measuring the amount of DIC in each vertical segment. The precedure would be as follows: (1) introduce carbon tracer into the sediment core through injection portals at regular vertical intervals; (2) allow several days for the tracer to equilibrate between DIC and particulate fractions; (3) terminate the experiment by freezing and slicing into segments; 


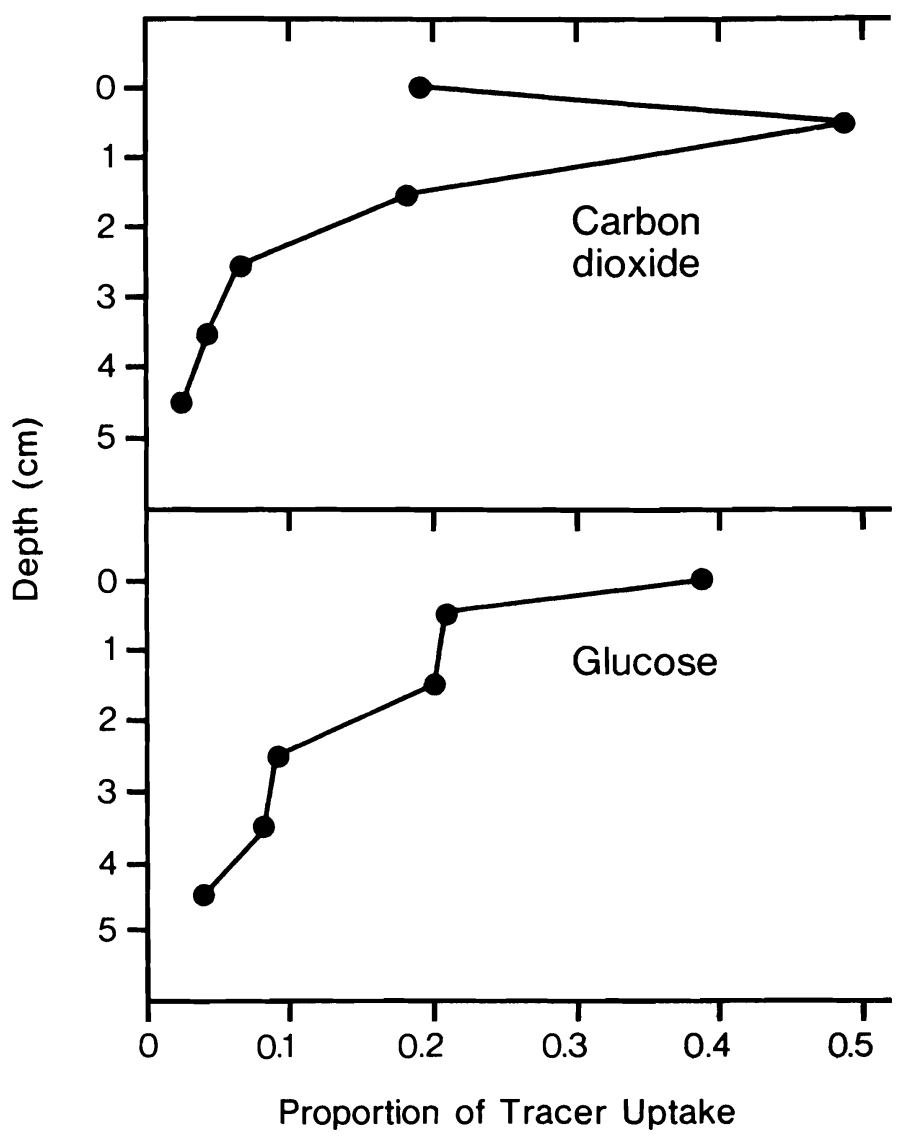

Fig. 6. Vertical distribution of microbial activity, as measured by the uptake of ${ }^{14} \mathrm{CO}_{2}$ and $\left[{ }^{14} \mathrm{C}\right]$ glucose by sediment microorganisms.

(4) measure the amount of carbon tracer in the DIC and particulate fractions of each segment; (5) directly measure the amount of DIC in each segment by means of infrared gas analysis; (6) estimate the amount of carbon in the living particulate fraction of each vertical segment by using the simple proportion described under Methods. Because of the direct DIC calibration in each vertical segment, estimates of particulate carbon should be valid reflections of the living biomass even if complete vertical equilibrium has not been attained.

\section{Acknowledgements}

I thank my colleagues in the Marion Lake Project (Institute of Resource Ecology, University of British Columbia) for their collaboration and support. The experiments were done in collaboration with Pierre Kleiber. Kent Burnison made autoradiography observations, and Elizabeth Enns and Itsuo Yesaki provided laboratory assistance. Kenneth Hall, Kent Burnison, and Pierre Kleiber reviewed early versions of the manuscript. The study was funded by the National
Research Council of Canada under the auspices of the Canadian International Biological Program.

\section{References}

AtLAS, R. M., AND R. BARTHA. 1981. Microbial ecology: fundamentals and applications. Addison-Wesley, Reading, MA. 560 p.

Burnison, B. K., AND K. T. Perez. 1974. A simple and inexpensive method for the dry combustion of ${ }^{14} \mathrm{C}$-labelled biological materials. Ecology 55 899-902.

Collins, V. G. 1977. Methods in sediment microbiology. Adv. Aquat Microbiol. 1: 219-272.

Dick, M. W. 1971. The ecology of Saprolegniaceae in lentic and littoral muds with a general theory of fungi in the lake ecosystem. J. Gen. Microbiol. 65 325-337.

EFFoRD, I. E. 1972. An interim review of the Marion Lake Project, p. 89-109. In Z. Kajak and A. Hillbricht-Ilkowska [ed.] Productivity problems of freshwaters. Kazimierz Dolny, Poland.

GRUENDLING, G. K. 1971. Ecology of the epipelic algal communities in Marion Lake, British Columbia. J. Phycol. 1: 239-249.

Hall, K. J., AND K. D. HyATT. 1974. Marion Lake (IBP) - from bacteria to fish. J. Fish. Res. Board Can. 31: 893-911.

HALl, K. J., P. M. KLeIBER, AND I. YeSAKI. 1972. Heterotrophic uptake of organic solutes by micro-organisms in the sediment. In U. MelchioniSantolini and J. W. Hopton [ed.] Detritus and its role in aquatic ecosystems. Mem. Ist. Ital. Idrobiol. 29 (Suppl.): 441-470.

HoBBIE, J. E., AND C. LEE. 1980. Microbial production of extracellular material: importance in benthic ecology, p. 341-346. In K. R. Tenore and B. C. Coull [ed.] Marine benthic dynamics. University of South Carolina Press, Columbia, SC

HoEbel, M. F. 1978. The role of meiofauna in the benthic community of a small, oligotrophic lake. Ph.D. thesis, University of British Columbia, Vancouver, B.C. $196 \mathrm{p}$

Holm-HaNSEN, O., AND C. R. Booth. 1966. The measurement of adenosine triphosphate in the ocean and its ecological significance. Limnol. Oceanogr. 11: 510-519.

JONES, J. G. 1974. Some observations on direct counts of freshwater bacteria obtained with a fluorescent microscope. Limnol. Oceanogr. 19: 540-543. 1977. The study of aquatic microbial communities, p. 1-30. In F. A. Skinner and J. M. Shewan [ed.] Aquatic microbiology. Academic Press, London.

KARL, D. M. 1980. Cellular nucleotide measurements and applications in microbial ecology. Microbiol. Rev. 44: 739-796.

Kool, R. 1975. The ecology of the ciliated protozoa of Marion Lake, British Columbia. M.Sc. thesis, University of British Columbia, Vancouver, B.C. $55 \mathrm{p}$.

Marten, G. G., P. M. Kleiber, AND J. K. Reid. 1975. A computer program for fitting tracer kinetic and other differential equations to data. Ecology 56: $752-754$.

Perry, E. A. 1974. The biomass and activity of benthic bacteria in Marion Lake, British Columbia. M.Sc. thesis. University of British Columbia, Vancouver, B.C. 98 p.

Puleo, J. R., M. S. Favaro, and N. J. Peterson. 1967. Use of ultrasonic energy in assessing microbial contamination on surfaces. Appl. Microbiol. 15: $1345-1351$.

RodinA, A. G. 1972. Methods in aquatic microbiology. University Park Press, Baltimore, MD. $461 \mathrm{p}$.

Sorokin, Y. I., AND H. Kadota. 1972. Techniques for the assessment of microbial production and decomposition in fresh waters. Blackwell Scientific Publications, Oxford. $112 p$.

StrZelczyk, E., O. Leniarska, and W. Donderski. 1974. Studies on metabolic activity of benthic bacteria isolated from three lakes. Acta Microbiol. Pol. Ser. B. Microbiol. Appl. 6: 125-132. 